\title{
Columnar cell lesions associated with breast calcifications on vacuum-assisted core biopsies: clinical, radiographic, and histological correlations
}

\author{
Rebecca Senetta ${ }^{1}$, Pier Paolo Campanino ${ }^{2}$, Giovanna Mariscotti ${ }^{2}$, Sara Garberoglio ${ }^{2}$, \\ Lorenzo Daniele ${ }^{1}$, Francesca Pennecchi ${ }^{3}$, Luigia Macrí ${ }^{1}$, Martino Bosco ${ }^{1}$, \\ Giovanni Gandini ${ }^{2}$ and Anna Sapino ${ }^{1}$ \\ ${ }^{1}$ Department of Biomedical Sciences and Human Oncology, University of Turin, Turin, Italy; ${ }^{2}$ Institute of \\ Diagnostic and Interventional Radiology, University of Turin, Turin, Italy and ${ }^{3}$ Istituto Nazionale di Ricerca \\ Metrologica, Turin, Italy
}

\begin{abstract}
Columnar cell lesions of the breast are increasingly recognized at mammography for their tendency to calcify. We studied 392 vacuum-assisted core biopsies performed solely for calcifications to evaluate the frequency of columnar cell lesions, their relationship with radiological risk, appearance of calcifications, and clinical data. Management and follow-up of columnar cell lesions without and with atypia (flat epithelial atypia) was analyzed. Cases with architectural atypia (cribriform spaces and/or micropapillae) were excluded from flat epithelial atypia. Calcifications were within the lumen of acini affected by columnar cell lesions in 137 out of 156 biopsies diagnosed with some columnar cell lesions. These represented $37 \%$ of vacuum-assisted core biopsies and $62 \%$ of low radiological risk (BI-RADS3) calcifications. High-risk (BI-RADS5) calcifications were never associated with columnar cell lesions. Age and menopausal status were comparable in columnar and in not-columnar cell lesions. Atypia was associated with long-term hormone replacement therapy in both lesions. Surgical biopsy was recommended for all cases with atypia. Flat epithelial atypia, as the only histological findings on vacuum-assisted core biopsies, was never associated with malignancy at surgery. In conclusion, we suggest that surgical excision is not mandatory when flat epithelial atypia is found as the most advanced lesion on vacuum-assisted core biopsy performed for low radiological risk calcifications, and that women should be advised of the possible hormone dependency of this entity.
\end{abstract}

Modern Pathology (2009) 22, 762-769; doi:10.1038/modpathol.2009.21; published online 13 March 2009

Keywords: columnar cell lesions; flat epithelial lesion; calcifications

Stereotactic vacuum-assisted core biopsy is currently used to diagnose indeterminate or suspicious breast calcifications that are histologically related to a spectrum of breast lesions encompassing ductal carcinomas in situ and preneoplastic and benign lesions. Often this type of calcification resides in so-called 'columnar cell lesions', ${ }^{1}$ entities characterized by the presence of columnar epithelial cells lining the terminal duct lobular units that typically show flocculant or secretory material and microcalcifications in the lumen. The Breast Imaging

Correspondence: A Sapino, MD, Professor of Pathology, Department of Biomedical Sciences and Human Oncology, University of Turin, Via Santena 7, 10126 Turin, Italy.

E-mail: anna.sapino@unito.it

Received 27 October 2008; revised and accepted 5 February 2009; published online 13 March 2009
Reporting and Data System (BI-RADS) ${ }^{2}$ has standardized the description and management of findings identified on mammograms, thereby facilitating communication between radiologists and referring physicians. However, to our knowledge, there are no specific studies evaluating whether specific calcification descriptors are associate with columnar cell lesions.

Columnar cell lesions have been described under a variety of names. ${ }^{3-7}$ According to Schnitt and Vincent-Salomon, ${ }^{1}$ columnar cell lesions have been grouped into the categories of columnar cell change and columnar cell hyperplasia without or with atypia. Other authors ${ }^{8}$ have proposed a subcategorization of columnar cell lesions depending on the presence of architectural and/or cytological atypia. The unifying term 'flat epithelial atypia' has been proposed by the World Health Organization 
Working Group on the Pathology and Genetics of Tumors of the Breast ${ }^{9}$ for columnar cell lesions with low-grade cytological atypia.

From a biological point of view, columnar cell lesions are low-grade proliferating lesions that invariably express estrogen receptors. ${ }^{10}$ A recent experimental study indicates that columnar cell lesions exhibit a hyperresponsive phenotype in the presence of estrogen and atypical proliferation, leading to flat epithelial atypia, may be promoted by exogenous $17 \beta$-estradiol exposure. ${ }^{11}$ On the other hand, it has been shown that the columnar cell lesions frequently coexist with and show the same genetic alterations of hormonedependent lesions, such as low-grade ductal carcinoma in situ (particularly, micropapillary and cribriform type), lobular intraepithelial neoplasia, and invasive tubular carcinoma. ${ }^{8,12,13}$ All these data may be considered for postmenopausal women with a history of columnar cell lesions who are currently receiving or considering for hormone replacement therapy. Moreover, several experts in breast pathology underline that there is an urgent need for large, comprehensive studies describing more accurately the risk of finding malignant diseases after a diagnosis of columnar cell lesions on core biopsy specimens. ${ }^{14,15}$

Taking all these data together, the aims of our study were the following: (1) to evaluate the frequency of columnar cell lesions in the routine diagnosis of a series of vacuum-assisted core biopsies carried out for radiological calcifications; (2) to correlate the patient's clinical data (age and use of hormone replacement therapy) with the histological findings; (3) to evaluate whether specific calcification descriptors and BI-RADS categories correlate with columnar cell lesions; and (4) to define the management of patients, throughout the analysis of clinical and surgical follow-up.

\section{Materials and methods}

\section{Patients}

From January 2004 to June 2006, 421 image-guided stereotactic vacuum-assisted core biopsies were performed in 418 women. To ensure accurate characterization of the calcifications and appropriate correlation with histology and follow-up, we restricted the study to 392 women with calcifications as the only mammographic lesion while excluded 26 women carrying calcifications associated with opacities, structural thickening, or architectural distortion. Patients were divided into two groups, 156 with a diagnosis of columnar cell lesions with or without atypia, either pure or associated with other lesions, and 236 with lesions not associated with columnar cells (not-columnar cell lesions). The age and the use of hormone replacement therapy were considered in the two groups.

\section{Radiological Data}

The selection of lesions to be submitted to stereotactic vacuum-assisted core biopsy was not fully centralized but also requested by outside institutions to our center. Mammograms of women sent to our center for vacuum-assisted core biopsy were reviewed and reclassified. The ideal radiological risk for this biopsy procedure was BI-RADS category 4. Vacuum-assisted core biopsy was also performed for patients with likely benign BI-RADS category 3 calcifications that could not be traced back on previous mammograms or were present in addition to an already known calcification or cluster. BI-RADS category 5 (highly suggestive of malignancy) was sampled only in cases in which fine needle aspiration biopsy had an inconsistent response. Vacuum-assisted core biopsy was performed under stereotactic guidance using the Fischer Mammotest prone table (Fischer Imaging, Denver, CO, USA) in combination with the Mammotome (Ethicon Endo-Surgery, Cincinnati, OH, USA) probe device mounting the 11-gauge needle. The number of core tissue specimens per case ranges from 6 to 18 and radiography of the specimens was performed in each case to verify the presence of the calcifications. Two radiologists (GM and PPC) experienced in breast imaging and blinded to the histological diagnosis reviewed and established a consensus on all mammograms.

\section{Histological Data}

The cores with and without calcifications on specimen radiograms were separately submitted for pathological examination. Four sections were routinely cut, and additional sections were examined if needed.

For the study purposes, each case was reviewed by dedicated breast pathologists (AS and LM) blinded to the radiological data. The location of calcifications within or outside columnar cell lesions was also recorded to further assess the correspondence between the radiological calcifications and histological findings.

To simplify the histological classification of columnar cell lesions, we diagnosed columnar cell change and columnar cell hyperplasia without atypia as 'columnar cell lesions without atypia' whereas those with atypia as flat epithelial atypia. Following recent suggestions, ${ }^{14,15}$ we included in the flat epithelial atypia only lesions exhibiting monomorphic flat proliferation of atypical cells within the terminal duct lobular units with a slight loss of polarity or stratified nuclei. Lesions with complex architectural patterns such as cribriform spaces or micropapillae, according to the extent and degree of these, were placed within the atypical ductal hyperplasia or low-grade ductal in situ carcinoma. According to the European Guideline for breast screening pathology, ${ }^{16}$ samples with 
benign lesions but without calcifications on the core biopsy specimens were classified as inadequate B1; columnar cell lesions without atypia as B2; flat epithelial atypia and columnar cell lesions without atypia associated with lobular intraepithelial neoplasia or atypical ductal hyperplasia or papillomas as B3; and any columnar cell lesions associated with carcinoma in situ or invasive carcinoma were classified as B5a or B5b, respectively. We decided to classify flat epithelial atypia involving more than four vacuum-assisted core biopsy samples as B4.

\section{Patient Management}

To define the management of patients, the radiologist, the pathologist, and the surgeon routinely discussed all cases at multidisciplinary meetings. For benign lesions, classified as B2, imaging followup was suggested within 12 months as it is recommended in mammographic practice audits. ${ }^{2}$ Patients with atypical lesions B3 were discussed and recommended for surgery or radiological follow-up within 12 months depending on the presence or absence of residual calcifications on postvacuum-assisted core biopsy radiograms and on the type of lesions associated with columnar cells. B4 and B5 lesions were sent to surgical excision. Pathological findings at the patient's definitive surgical intervention served as the reference standard for atypical or malignant lesions.
Statistical significance was defined as $P<0.05$. The analysis was performed using R, statistical software that is freely available from the Internet (http:// cran.r-project.org/).

\section{Results}

\section{Localization of Calcifications in Columnar Cell Lesions}

First of all, to ensure that columnar cell lesions were not associated by mere chance to the calcifications target of the vacuum-assisted core biopsy, we assessed the histological location of the calcifications in 156 cases diagnosed with columnar cell lesions either as the main lesion or associated with other pathological entities. Nineteen cases showing only stromal calcium deposits or luminal calcifications not within columnar cell lesions were excluded. Out of the 156 cases, 137 (88\%) showed granular or laminar calcifications featuring psammomatous bodies or calcified amorphous intraluminal secretions within the lumen (Figure 1). In particular, in 3 cases of the B5 category, calcifications were present in columnar cell lesions only and absent in the associated malignancy and in 11 cases the same type of calcifications were histologically located within both columnar cell lesions and ductal carcinoma in situ. One case showing calcifications only in ductal carcinoma in situ was excluded from the analysis.

\section{Statistical Analysis}

\section{Clinical Data}

Statistical analysis was performed using the twotailed Fisher's exact test with Bonferroni correction.

The final cohort, excluding the 19 cases with calcifications outside the lumen of columnar cell
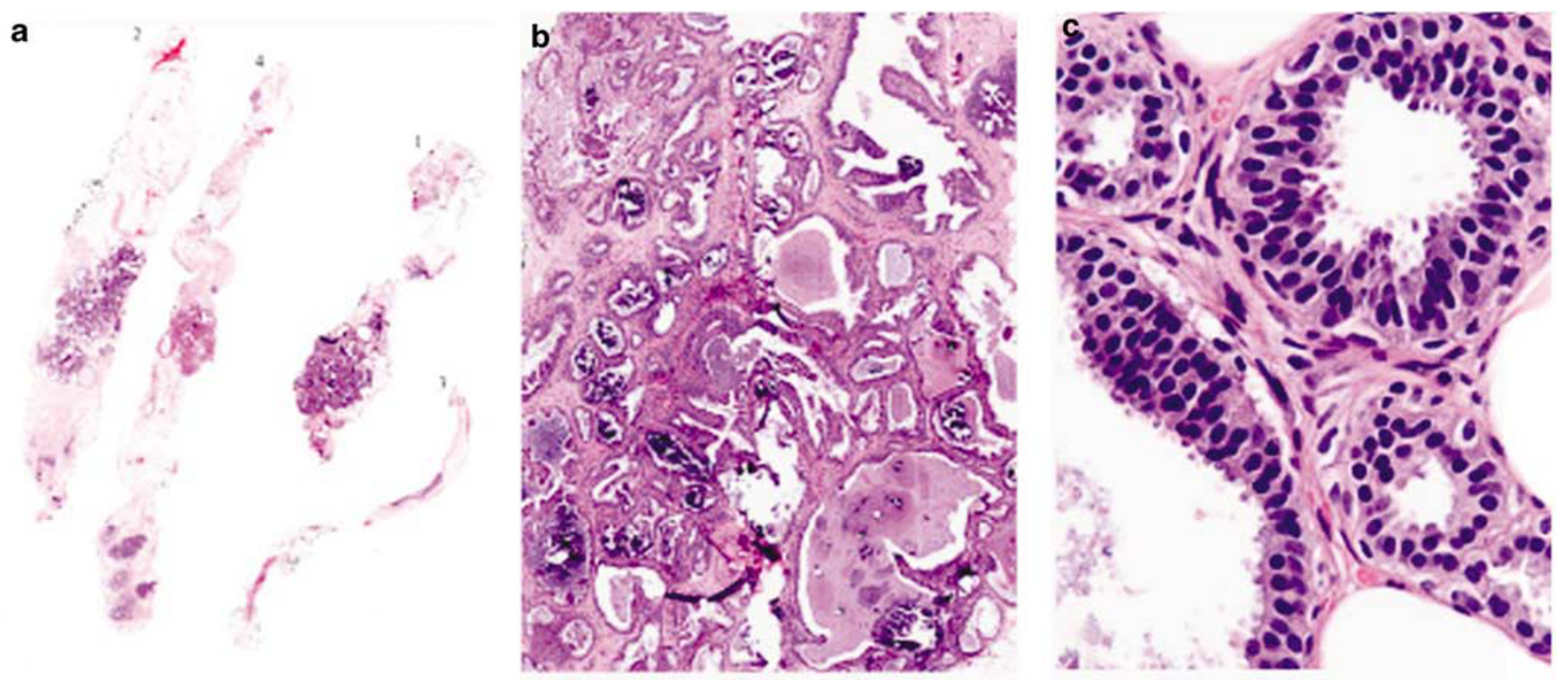

Figure 1 Hematoxylin and eosin stained sections of stereotactic vacuum-assisted core biopsy performed on radiological calcifications described in Figure 2. Low power magnification of specimens. Calcifications are present in samples 1 and 2 (a). Higher magnification $(\times 10)$ of sample 1 shows that in the same columnar cell lesions are calcified amorphous intraluminal secretions, psammomatous bodies, and granular calcifications (b). The epithelium shows cellular stratification, low-grade cytologic atypia and apical cytoplasmic snouts typical of flat epithelial atypia (B3) $(\times 40)(\mathbf{c})$. 
lesions, was of 373 women. Columnar cells with luminar calcifications represented the target of $37 \%$ of stereotactic vacuum-assisted core biopsy (Table 1). Of the 373 women, 209 were enrolled from screening programs and 264 were referred by their physician or sent to our institution from other radiology centers. The proportion of columnar cell lesions was comparable in screening and nonscreening patients. The mean ages of women with columnar and not-columnar cell lesions were 53.9 (range 36-71 years) and 57.2 years (range 40-80 years), respectively.

The correlation with hormone replacement therapy was evaluated only in the screening patients, because these data were not available for all of the patients in the nonscreening series (Table 1). In this subset, the proportion of hormone replacement treatment was comparable in columnar and not-columnar cell lesions. No differences were observed between the number of atypical and nonatypical lesions in the two groups. However, patients carrying atypical lesions in both groups were exposed to hormone replacement therapy for a longer time (median exposure time in atypical lesions 5 years vs 2 years in benign lesions).

\section{Radiological Risk (BI-RADS), Morphology, and Distribution of Radiological Calcifications}

Statistically significant differences $(P<0.001)$ were observed in the BI-RADS categories between the calcifications related and unrelated to columnar cell lesions. BI-RADS3 was due to columnar cell lesions in about two-third of the cases (Table 2) and in particular atypia was encountered in $20 \%$ of these cases (14 B3 out of 71 BI-RADS3). In contrast, only three cases of BI-RADS3 in the not-columnar cell

Table 1 Clinical features according to the diagnosis of columnar cell lesions or not-columnar cell lesions on stereotactic vacuumassisted core biopsies

\begin{tabular}{lrr}
\hline & CCLs (\%) & Not-CCLs (\%) \\
\hline Total & $137 / 373(37)$ & $236 / 373(63)$ \\
Screen-detected & $79(38)$ & $130(62)$ \\
Not screen-detected & $58(35)$ & $106(64)$ \\
Age at VACB (years) & & \\
$\quad<40$ & $2(1)$ & $0(0)$ \\
$40-49$ & $22(16)$ & $27(11)$ \\
$50-59$ & $83(60)$ & $131(55)$ \\
$60-69$ & $27(20)$ & $15(6)$ \\
$>70$ & $3(2)$ & $18(14)$ \\
HRT in 209 women of screening program & $112(86)$ \\
Yes & $14(18)$ & $65(82)$ \\
No &
\end{tabular}

CCLs: columnar cell lesions; HRT: hormone replacement therapy; VACB: vacuum-assisted core biopsy. lesions were related to atypical B3 lesions and the remaining cases were benign. Approximately two-third of BI-RADS4 and the few cases of BI-RADS5 submitted to vacuum-assisted core biopsy were due to not-columnar cell lesions (Table 2).

On the contrary, no statistically significant differences $(P=0.08)$ in morphological patterns were observed between calcifications associated and unassociated with columnar cells (Table 3). However, none of the columnar cell lesions per se was associated with linear or branching calcifications $(P=0.02)$.

In columnar cell lesions, calcifications were clustered with a lobular distribution (Figures 2a and b) and with an extension $<1 \mathrm{~cm}$. In 10 cases one to three clusters of calcifications were present in one quadrant. In these cases vacuum-assisted core biopsy was performed either on the cluster with higher radiological risk or on a single cluster if they showed the same risk.

\section{Histological Category (B)}

Columnar cell lesions represented the major source of the B3 histological category (60 vs 40\%) (Table 4), whereas the B2 and B4/B5 were mainly the result of not-columnar cell lesions $(P \ll 0.001)$.

\section{Treatment and Follow-Up}

Patients with columnar cell lesions without atypia (B2) were recommended for follow-up, except for

Table 2 Correlations of histological diagnosis (columnar cell lesions vs not-columnar cell lesions) and BI-RADS category of calcifications

\begin{tabular}{lccc}
\hline $\begin{array}{l}\text { Radiological } \\
\text { category }\end{array}$ & Total (\%) & $\begin{array}{c}\text { CCLs } \\
\text { number (\%) }\end{array}$ & $\begin{array}{c}\text { Not-CCLs } \\
\text { number (\%) }\end{array}$ \\
\hline BI-RADS3 & $71(19)$ & $44(62)$ & $27(38)$ \\
BI-RADS4 & $294(79)$ & $93(32)$ & $201(68)$ \\
BI-RADS5 & $8(2)$ & $0(0)$ & $8(100)$ \\
& \multicolumn{2}{c}{$P \ll 0.001$} &
\end{tabular}

CCLs: columnar cell lesions.

Table 3 Correlations of radiological morphology of calcifications and histological diagnosis of vacuum-assisted core biopsies

\begin{tabular}{|c|c|c|c|}
\hline $\begin{array}{l}\text { Calcification } \\
\text { morphology }\end{array}$ & Total (\%) & $\begin{array}{c}\text { CCLs } \\
\text { number (\%) }\end{array}$ & $\begin{array}{c}\text { Not-CCLs } \\
\text { number (\%) }\end{array}$ \\
\hline Amorphous/indistinct & $161(43)$ & $59(37)$ & $102(63)$ \\
\hline Fine pleomorphic ${ }^{\mathrm{a}}$ & $95(25)$ & $40(42)$ & $55(58)$ \\
\hline Linear or branching & $9(2)$ & $0(0)$ & $9(100)$ \\
\hline Others ${ }^{\mathrm{b}}$ & $108(29)$ & $38(35)$ & $70(65)$ \\
\hline
\end{tabular}

aPredominantly 'granular'.

${ }^{b}$ Round, powdery, large rodlike, and heterogeneous calcifications. CCL: columnar cell lesions. 

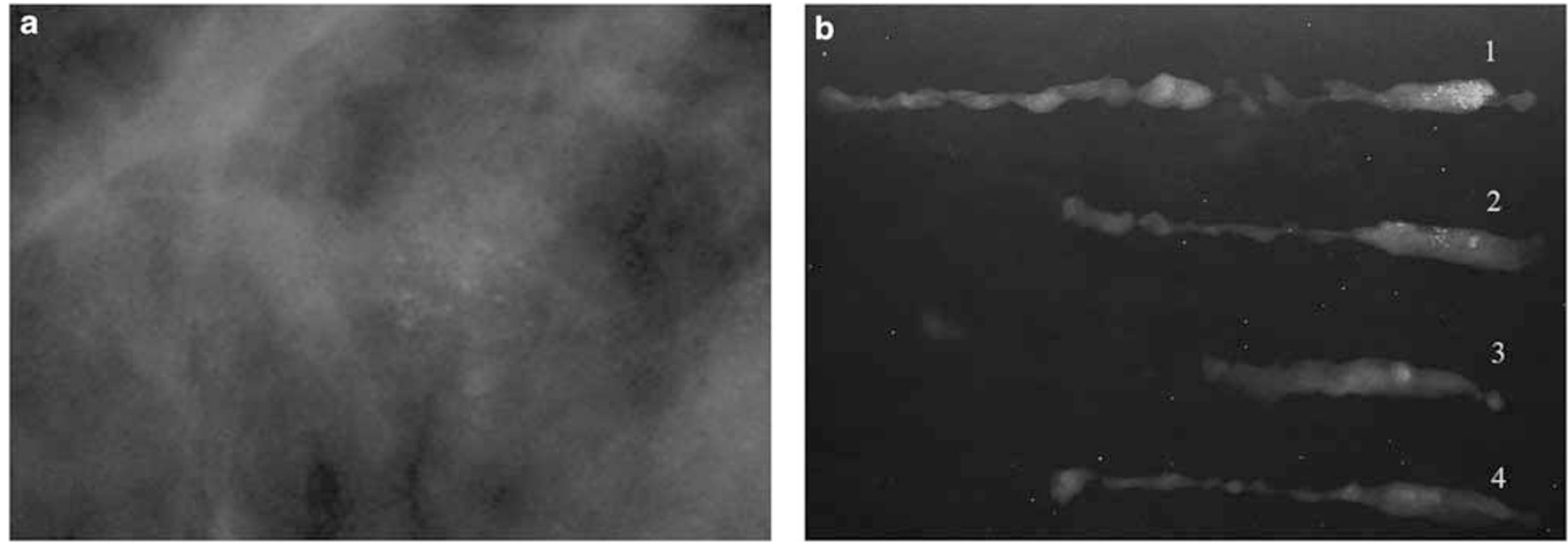

Figure 2 (a) Digital radiogram of Fischer Mammotest of BI-RADS3 clustered calcifications, $7 \mathrm{~mm}$ in the largest diameter, with indistinct morphology. (b) Radiogram of vacuum-assisted core biopsy specimens: clusters of calcifications are present on specimens 1 and 2.

Table 4 Correlations of histological diagnosis (columnar vs notcolumnar cell lesions) and 'B' category of stereotactic vacuumassisted core biopsies

\begin{tabular}{lccc}
\hline $\begin{array}{l}\text { Histological } \\
\text { category }\end{array}$ & $\begin{array}{c}\text { Total } \\
(\%)\end{array}$ & $\begin{array}{c}\text { CCLs number } \\
(\%)\end{array}$ & $\begin{array}{c}\text { Not-CCLs number } \\
(\%)\end{array}$ \\
\hline B1 & $6(2)$ & $0(0)$ & $6(100)$ \\
B2 & $207(55)$ & $68(33)$ & $139(67)$ \\
B3 & $86(23)$ & $52(60)$ & $34(40)$ \\
B4 & $8(2)$ & $3(37)$ & $5(62)$ \\
B5a & $53(14)$ & $13(24)$ & $40(75)$ \\
B5b & $13(3)$ & $1(8)$ & $12(92)$ \\
& \multicolumn{2}{c}{$P \ll 0.001$} \\
\end{tabular}

CCLs: columnar cell lesions.

five patients who underwent surgery because the area of calcifications exceeded $1 \mathrm{~cm}$ and could not be completely harvested by vacuum-assisted core biopsy (Table 5). The benign nature of all of these lesions was confirmed at definitive surgery. Following the European Guideline, ${ }^{16}$ surgical biopsy was recommended for all B3 cases, with the exception of one woman, with columnar cell lesions without atypia associated with a benign papilloma, who was recommended for follow-up because all calcifications were harvested during the biopsy procedure. Nine women with B3 lesions refused surgical excision. All of them were either free of disease or yielded unmodified radiograms at the mammographic follow-up (Table 5). Of the 41 patients with flat epithelial atypia (both B3 and B4) as the only histological finding on biopsy specimens, 36 underwent surgery. In 20 cases calcifications were still present on radiograms of the surgical specimens. Histological atypia was confirmed in $53 \%$ of flat epithelial atypia of the B3 category and in 2 out of 3 cases classified as B4. Specifically, atypical ductal hyperplasia (13\%), lobular intraepithelial neoplasia $(23 \%)$, and flat epithelial atypia $(34 \%)$, either as a single lesion or in association with the others, were still present on the surgical specimen. Benign papillomas were also present in $13(38 \%)$ of these cases. We recommended surgery for the 13 cases of columnar cell lesions without atypia or flat epithelial atypia associated with atypical ductal hyperplasia or lobular intraepithelial neoplasia (5 LIN1 and 6 LIN2). In one case associated with atypical ductal hyperplasia and in five cases associated with lobular intraepithelial neoplasia on core biopsy, residual lobular neoplastic foci not associated with calcifications were present in the surgical specimens. One case of columnar cell lesions without atypia associated with lobular intraepithelial neoplasia (LIN2) was upgraded to ductal carcinoma in situ and foci of lobular intraepithelial neoplasia of the same type were still present.

All patients with lesions in the B5 category underwent surgery. Malignancy was confirmed on the surgical specimen in 12 out of 13 cases. In one case, the low-grade ductal carcinoma in situ was completely removed by vacuum-assisted core biopsy (16 cores) and foci of lobular intraepithelial neoplasia were present in the final surgical samples. In two cases, the definitive histology was upgraded from ductal carcinoma in situ to well-differentiated invasive ductal carcinoma and to tubular carcinoma, respectively. Residual invasive ductal carcinoma, ductal carcinoma in situ, and atypical ductal hyperplasia were found in the surgical specimen of the single case of columnar cell lesions without atypia that was associated with invasion on vacuum-assisted core biopsy.

\section{Discussion}

Columnar cell lesion is one of the most common abnormalities in the adult breast. ${ }^{17,18}$ Assessment of the radiological and clinical significance of the 
Table 5 Histological correlations between stereotactic vacuum-assisted core biopsy and surgical excision in columnar cell lesions group

\begin{tabular}{|c|c|c|c|c|c|c|}
\hline & & \multirow[t]{2}{*}{ Number } & \multicolumn{3}{|c|}{ Histology at surgery } & \multirow{2}{*}{$\begin{array}{c}\text { Radiological FU (months) } \\
\text { Mean } 38 \pm 6.8\end{array}$} \\
\hline & & & Benign & $\begin{array}{c}\text { Atypia } \\
\text { (LIN/ADH/FEA) }\end{array}$ & $\begin{array}{c}\text { Malignancy } \\
(D C I S / I C)\end{array}$ & \\
\hline B2 & CCL without atypia & 68 & $5(7 \%)$ & - & - & $63(93 \%)$ \\
\hline \multirow[t]{4}{*}{ B3 } & FEA & 38 & $13(34 \%)$ & $20(53 \%)$ & - & $5(13 \%)$ \\
\hline & CCL without atypia and papilloma & 1 & - & - & - & $1(100 \%)$ \\
\hline & CCL without atypia or FEA with LIN & 11 & $2(18 \%)$ & $5(45 \%)$ & $1(9 \%)$ & $3(27 \%)$ \\
\hline & CCL without atypia or FEA with ADH & 2 & $1(50 \%)$ & $1(50 \%)$ & - & - \\
\hline B4 & Extensive FEA & 3 & $1(33 \%)$ & $2(67 \%)$ & - & - \\
\hline \multirow[t]{3}{*}{ B5 } & CCL without atypia and DCIS & 4 & - & - & $4(100 \%)$ & - \\
\hline & FEA and DCIS & 9 & - & $1(11 \%)$ & $8(89 \%)$ & - \\
\hline & CCL without atypia with IC & 1 & - & - & $1(100 \%)$ & - \\
\hline
\end{tabular}

CCL: columnar cell lesions; FEA: flat epithelial atypia; LIN: lobular intraepithelial neoplasia; ADH: atypical ductal hyperplasia; DCIS: ductal carcinoma in situ; IC: invasive carcinoma; FU: follow up.

columnar cell lesions has been hampered by variations in the terminology used to describe these histological entities and by the limited number of cases that have been studied in a systematic fashion in the presurgical setting. This is the first study correlating columnar cell lesions and radiological calcifications on a series of 392 consecutive stereotactic vacuum-assisted core biopsies. Taking into account the actual histological location of calcifications associated with a diagnosis of columnar cell lesions, we showed that these lesions represent the background of about $37 \%$ of the radiological calcifications, a percentage slightly lower than that previously reported. ${ }^{3}$ The radiological shape of these calcifications cannot be used to absolutely differentiate columnar from not-columnar cell lesions, although linear or branching calcifications are never found within columnar cell lesions per se. Instead, the clustered amorphous/indistinct or granular radiological morphology of calcifications may be explained by considering that columnar cell lesions develop in multiple terminal duct lobular units with calcium deposits inside the lumen containing secretory material. ${ }^{1}$ Over time, these deposits become tighter, with a laminar concentric appearance and give rise to histological psammomatous calcifications, typical of both benign and malignant lesions. ${ }^{19}$ On the other hand, considering the radiological risk category, we showed that columnar cell lesions are the major source of BIRADS3, but this low risk may be associated with histological atypia in about $20 \%$ of the cases, whereas calcifications with the same radiological risk are rarely associated with atypia in the notcolumnar cell lesions. In addition, the follow-up study showed that classifying flat epithelial atypia involving more than four cores as B4 is rather arbitral, because none of the three cases of our series showed malignancy on the surgical samples.

The appropriate pathology work-up and clinical management of patients, whose presurgical speci- mens show columnar cell lesions, are evolving as information regarding these lesions begins to accumulate. First of all, morphological criteria to differentiate flat epithelial atypia from other types of intraepithelial proliferating lesions such as atypical ductal hyperplasia are now established. ${ }^{14,15}$ However, columnar cell lesions may be associated with other preneoplastic or neoplastic entities. The prevalence of atypical ductal hyperplasia associated with columnar cell lesions in vacuum-assisted core biopsies in the present series is quite low, but on the final surgical specimens, we confirmed that atypical ductal hyperplasia and lobular intraepithelial neoplasia were the most common accompanying lesions. ${ }^{20-22}$ In addition, our results show that small papillomas/papillomatosis of terminal duct lobular unit are often related to columnar cell lesions as well. In a recent study on a small series of core biopsies not-vacuum-assisted, ${ }^{23}$ it has been shown that flat epithelial atypia was associated with malignancy in 2 out of 11 cases. Our data show that vacuum-assisted core biopsy is more accurate compared to not-vacuum-assisted core biopsy avoiding false-negative results in low radiological risk calcifications.

We cannot confirm a prevalence of columnar cell lesions in women of younger age, as previously suggested. ${ }^{24}$ In addition, the low number of individuals taking hormone replacement therapy cannot allow any definitive conclusion on the relationship of columnar cell lesions with hormone exposure; however, an association with atypia and the length of hormone replacement therapy could be assumed. This hypothesis could have a rationale, considering that columnar cells express high levels of estrogen receptor but are low-proliferating cells. ${ }^{10}$ Because estrogen stimulates proliferation ${ }^{24}$ and suppresses apoptosis ${ }^{25}$ in normal cells, elevated estrogen receptor expression in columnar cell lesions may be a fundamental alteration leading to hyperplasia that occasionally progresses to atypia and cancer. ${ }^{26}$ In 
fact, columnar cell lesions are considered not obligate precursors of lobular and tubular carcinomas, ${ }^{12,20-22}$ two cancer histotypes closely related to hormone replacement therapy exposure. ${ }^{27}$ Interestingly, the results of a recent experimental study indicate that $17 \beta$-estradiol exposure of postmenopausal primates promotes proliferation of flat epithelial atypia. ${ }^{11}$

In conclusion, columnar cell lesions are never associated with BI-RADS5 category and linear or branching calcifications. Using specific histological criteria for diagnosis of flat epithelial atypia on stereotactic vacuum-assisted core biopsy specimens and in agreement with other authors, ${ }^{15}$ we suggest that (1) a multidisciplinary approach is essential for management of columnar cell lesions; (2) surgery has to be considered when columnar cell lesions without atypia or flat epithelial atypia are associated with other risk lesions, such as atypical ductal hyperplasia or lobular intraepithelial neoplasia, on vacuum-assisted core biopsy; and (3) an excision biopsy is not mandatory only when histopathological findings are concordant with the radiological features and flat epithelial atypia is found on stereotactic vacuum-assisted core biopsy as the most advanced lesion. However, considering that flat epithelial atypia is frequently multifocal and bilateral, ${ }^{15}$ patients should be advised of the possible hormonal dependency of this entity.

\section{Acknowledgements}

MURST 2008. Progetto Alfieri, Fondazione CRT 2007. Fondazione Cassa di Risparmio di Cuneo, Regione Piemonte. Associazione Italiana Ricerca sul Cancro (AIRC grant 2008). Ricerca Finalizzata Regione Piemonte 2008, Regione Piemonte-CIPE 2004 and MIUR-PRIN 2005.

\section{Conflict of interest}

None declared.

\section{References}

1 Schnitt SJ, Vincent-Salomon A. Columnar cell lesions of the breast. Adv Anat Pathol 2003;10:113-124.

2 American College of Radiology. Breast Imaging Reporting and Data System (BI-RADS), 4th edn. American College of Radiology: Reston, VA, 2003.

3 Fraser JL, Raza S, Chorny K, et al. Columnar alteration with prominent apical snouts and secretions: a spectrum of changes frequently present in breast biopsies performed for microcalcifications. Am J Surg Pathol 1998;22:1521-1527.

4 McLaren BK, Gobbi H, Schuyler PA, et al. Immunohistochemical expression of estrogen receptor in enlarged lobular units with columnar alteration in benign breast biopsies: a nested case-control study. Am J Surg Pathol 2005;29:105-108.

5 Oyama T, Maluf H, Koerner F. Atypical cystic lobules: an early stage in the formation of low-grade ductal carcinoma in situ. Virchows Arch 1999;435:413-421.

6 Arpino G, Laucirica R, Elledge RM. Premalignant and in situ breast disease: biology and clinical implications. Ann Intern Med 2005;143:446-457.

7 Pinder SE, Provenzano E, Reis-Filho JS. Lobular in situ neoplasia and columnar cell lesions: diagnosis in breast core biopsies and implications for management. Pathology 2007;39:208-216.

8 Simpson PT, Gale T, Reis-Filho JS, et al. Columnar cell lesions of the breast: the missing link in breast cancer progression? A morphological and molecular analysis. Am J Surg Pathol 2005;29:734-746.

9 WHO Tavassoli FA Hoefler H, Rosai J, et al. Intraductal proliferative lesions. In: Tavassoli FA, Devilee P (eds). Pathology and Genetics of Tumours of the Breast and Female Genital Organs. IARC Press: Lyon, France, 2003, pp 63-73.

10 Tremblay G, Deschênes J, Alpert L, et al. Overexpression of estrogen receptors in columnar cell change and in unfolding breast lobules. Breast J 2005;11:326-332.

11 Wood CE, Hester JM, Appt SE, et al. Estrogen effects on epithelial proliferation and benign proliferative lesions in the postmenopausal primate mammary gland. Lab Invest 2008;88:938-948.

12 Abdel-Fatah TM, Powe DG, Hodi Z, et al. High frequency of coexistence of columnar cell lesions, lobular neoplasia, and low grade ductal carcinoma in situ with invasive tubular carcinoma and invasive lobular carcinoma. Am J Surg Pathol 2007;31:417-426.

13 Moinfar F, Man YG, Bratthauer GL, et al. Genetic abnormalities in mammary ductal intraepithelial neoplasia-flat type ('clinging ductal carcinoma in situ'): a simulator of normal mammary epithelium. Cancer 2000;88:2072-2081.

14 Pinder SE, Reis-Filho JS. Non-operative breast pathology: columnar cell lesions. J Clin Pathol 2007;60:1307-1312.

15 Martel M, Barron-Rodriguez P, Tolgay Ocal I, et al. Flat DIN 1 (flat epithelial atypia) on core needle biopsy: 63 cases identified retrospectively among 1,751 core biopsies performed over an 8-year period (19921999). Virchows Arch 2007;451:883-891.

16 Perry N, Broeders M, de Wolf C, et al. European Commission. European Guidelines for Quality Assurance in Breast Cancer Screening and Diagnosis. (2006), 4th edn. Office for Official Publications of the European Communities: Luxembourg.

17 Nasser SM. Columnar cell lesions: current classification and controversies. Semin Diagn Pathol 2004;21:18-24.

18 Lee S, Mohsin SK, Mao S, et al. Hormones, receptors, and growth in hyperplastic enlarged lobular units: early potential precursors of breast cancer. Breast Cancer Res 2005;8:R6.

19 Foschini MP, Fornelli A, Peterse JL, et al. Microcalcifications in ductal carcinoma in situ of the breast: histochemical and immunohistochemical study. Hum Pathol 1996;27:178-183.

20 Rosen PP. Columnar cell hyperplasia is associated with lobular carcinoma in situ and tubular carcinoma. Am J Surg Pathol 1999;23:1561.

21 Sahoo S, Recant WM. Triad of columnar cell alteration, lobular carcinoma in situ, and tubular carcinoma of the breast. Breast J 2005;11:140-142. 
22 Leibl S, Regitnig P, Moinfar F. Flat epithelial atypia (DIN 1a, atypical columnar change): an underdiagnosed entity very frequently coexisting with lobular neoplasia. Histopathology 2007;50: 859-865.

23 Nofech-Mozes S, Holloway C, Hanna W. The role of cytokeratin $5 / 6$ as an adjunct diagnostic tool in breast core needle biopsies. Int J Surg Pathol 2008;16:399-406.

24 Anderson E, Clarke RB. Steroid receptors and cell cycle in normal mammary epithelium. J Mammary Gland Biol Neoplasia 2004;9:3-13.
25 Gompel A, Somai S, Chaouat M, et al. Hormonal 769 regulation of apoptosis in breast cells and tissues. Steroids 2000;65:593-598.

26 Frech MS, Halama ED, Tilli MT, et al. Deregulated estrogen receptor alpha expression in mammary epithelial cells of transgenic mice results in the development of ductal carcinoma in situ. Cancer Res 2005;65:681-685.

27 Reeves GK, Beral V, Green J, , et al., Million Women Study Collaborators. Hormonal therapy for menopause and breast-cancer risk by histological type: a cohort study and meta-analysis. Lancet Oncol 2006;11:910-918. 